\title{
Semi-transparent a-SiC:H solar cells for self-powered photovoltaic-electrochromic devices
}

\author{
John N. Bullock * , Clemens Bechinger, David K. Benson, Howard M. Branz \\ National Renewable Energy Laboratory, Golden, CO 80401, USA
}

\begin{abstract}
Self-powered 'smart' windows for active control of building heating and cooling represent a potential new market for amorphous-silicon based photovoltaics. Retrofit applications to existing windows are facilitated by the tandem photovoltaic-electrochromic (PV-EC) device, in which a wide-gap amorphous silicon-based alloy (a-SiC:H) photovoltaic cell is deposited together with an EC optical transmittance modulator in a monolithic coating on a single substrate. In this paper, studies of transparent wide-gap a-SiC:H thin-films and $\mathrm{p}-\mathrm{i}-\mathrm{n}$ cells designed for use in the PV-EC device are described. Using optimized a-SiC:H i-layer material, $J_{\mathrm{sc}}$ of $3.9 \mathrm{~mA} / \mathrm{cm}^{2}$ and $V_{\mathrm{oc}}$ of $0.92 \mathrm{~V}$ is achieved, adequate to color our low-voltage Li-based EC devices in less than one minute, and good progress toward the required transparency is shown.
\end{abstract}

\section{Introduction}

Self-powered, smart windows are a potential new a-Si:H based photovoltaic (PV) application. A variable transmittance window coating, operated as part of an intelligent building energy management system, can provide substantial total energy savings [1-3]. These windows utilize an electro-optic modulator based on electrochromic (EC) thin films that exhibit well-controlled and reversible changes in optical absorption under low applied voltages.

Current proposals call for a connection to an external power source, either a battery at each window or low-voltage wiring throughout the building. However, simulations show that a building energy management system can be highly effective when constructed from independent, smart components [4]. This system replaces centralized intelligent control

\footnotetext{
Correspondence author. Tel: + 1-303 3846698 ; fax: +1-303 3846531 : e-mail: jbullock@nrel.gov.
}

with distributed smart components, each reacting to local occupant and energy management requirements. The monolithic, tandem PV-EC device [5], being self-powered, can be an important component in such a system [4]. In this paper, we describe progress toward a tandem PV-EC device composed of a wide-gap amorphous $\mathrm{SiC}$ alloy (a-SiC:H) PV cell and an all solid-state EC device based on $\mathrm{Li}$ doped $\mathrm{WO}_{3}$.

Since its discovery in 1969 , electrochromism in transition metal oxides has been studied [6]. Still, the fundamental mechanism of the change in optical properties remains controversial [7-10]. For device engineering, however, a simple phenomenological model suffices. The features of an EC material (e.g. $\mathrm{WO}_{3}$ ) that are important for EC device operation are that (1) a reversible insertion-phase compound is formed with small, mobile ions (e.g. $\mathrm{Li}^{+}$) and (2) each ion inserted induces an optical absorption center $[11,12]$. Thus, by inserting and extracting $\mathrm{Li}^{+}$, the optical absorption of a $\mathrm{WO}_{3}$ film can be continu- 


\begin{tabular}{|c|}
\hline $\mathrm{SnO}_{2}(\mathrm{~A})$ \\
\hline ion storage material $\left(\mathrm{V}_{2} \mathrm{O}_{5}\right)$ \\
\hline ion conductor $\left(\mathrm{MgF}_{2}\right)$ \\
\hline electrochromic material $\left(\mathrm{WO}_{3}\right)$ \\
\hline $\mathrm{SnO}_{2}(\mathrm{~B})$ \\
\hline $\mathrm{n}$-type $\mu \mathrm{c}-\mathrm{SiC}: \mathrm{H}$ \\
\hline intrinsic a-SiC:H \\
\hline $\mathrm{p}$-type a-SiC:H \\
\hline $\mathrm{SnO}_{2}(\mathrm{C})$ \\
\hline substrate \\
\hline
\end{tabular}

Fig. 1. Schematic structure of the proposed monolithic photovoltaic-electrochromic device.

ously and reversibly varied. Transport of $\mathrm{Li}^{+}$in and out of a $\mathrm{WO}_{3}$ film is balanced by an equal but opposite electron current as given by the reversible reaction

$\mathrm{WO}_{3}+x \mathrm{e}^{-}+x \mathrm{Li}^{+} \leftrightarrow \mathrm{Li}_{x} \mathrm{WO}_{3}$,

which converts transparent $\mathrm{WO}_{3}$ into optically absorbing $\mathrm{Li}_{x} \mathrm{WO}_{3}$ and back again. The concentration of $\mathrm{Li}^{+}, x$, determines the absorption coefficient of the $\mathrm{Li}_{x} \mathrm{WO}_{3}$ film and thus the transparency of the EC device. The internal chemical potential of $\mathrm{Li}^{+}$in the $\mathrm{WO}_{3}$ film is also determined by $x$, while the total external $\mathrm{Li}^{+}$chemical potential is the sum of the internal chemical potential and any applied electrostatic potential [13].

The upper half of Fig. 1 shows our EC device structure. The EC layer $\left(\mathrm{WO}_{3}\right)$ is joined by $\mathrm{MgF}_{2}$ to an ion storage layer $\left(\mathrm{V}_{2} \mathrm{O}_{5}\right)$, which accommodates $\mathrm{Li}^{+}$but does not change color. The $\mathrm{MgF}_{2}$ layer conducts $\mathrm{Li}^{+}$ions but is otherwise electrically insulating. A voltage bias applied to the $\mathrm{SnO}_{2}$ contact layers shifts the $\mathrm{Li}^{+}$chemical potential balance between the $\mathrm{WO}_{3}$ and $\mathrm{V}_{2} \mathrm{O}_{5}$ layers, causing $\mathrm{Li}^{+}$flow and a change in the coloration state of the device [13]. In the tandem PV-EC device, this potential is supplied by the PV cell integrated with the EC device, as shown in Fig. 1.

The PV cell in the PV-EC tandem device must have the following features: (1) sufficient transparency in the visible to allow an acceptable total window transmittance in the bleached state; (2) an open-circuit voltage $\left(V_{\text {oc }}\right)$ large enough to shift the $\mathrm{Li}^{+}$chemical potential balance in the EC device into the opaque state; and (3) a short-circuit current $\left(J_{\mathrm{sc}}\right)$ adequate to achieve EC coloration in a reasonable time (minutes). For the new, low-voltage EC devices we are developing [14], this means $V_{\text {oc }}>1 \mathrm{~V}$ and $J_{\mathrm{sc}}>0.1 \mathrm{~mA} / \mathrm{cm}^{2}$. For good visible transparency and color fidelity, we estimate that a cell transmittance of $70 \%$ at photon energies below $2.4 \mathrm{eV}$ will be required.

\section{Experimental procedures}

We prepared intrinsic a-SiC: $\mathrm{H}$ samples and $\mathrm{p}-\mathrm{i}-\mathrm{n}$ cells in a single-chamber radio-frequency (rf) diode glow-discharge reactor. The intrinsic samples were deposited from $\mathrm{SiH}_{4}$ and $\mathrm{CH}_{4}$ with varying $\mathrm{H}_{2}$ dilutions. The hydrogen dilution ratio $\left(\mathrm{H}_{2}\right.$ flow to

Table 1

Intrinsic a-SiC: $\mathrm{H}$ deposition conditions, carbon content, and selected electronic and optical properties

\begin{tabular}{|c|c|c|c|c|c|c|c|c|}
\hline $\begin{array}{l}\text { ID } \\
\#\end{array}$ & $\begin{array}{l}\mathrm{SiH}_{4} \\
(\mathrm{sccm})\end{array}$ & $\begin{array}{l}\mathrm{CH}_{4} \\
(\mathrm{sccm})\end{array}$ & $\begin{array}{l}\mathrm{H}_{2} \\
(\mathrm{sccm})\end{array}$ & $\begin{array}{l}\text { Power } \\
\text { (W) }\end{array}$ & $\begin{array}{l}\text { Pressure } \\
\text { (Torr) }\end{array}$ & $\begin{array}{l}E_{\mathrm{st}} \\
(\mathrm{eV})\end{array}$ & $\begin{array}{l}\sigma_{\mathrm{ph}} \\
(\mathrm{nS} / \mathrm{cm})\end{array}$ & $\begin{array}{l}\sigma_{\mathrm{ph}} / \sigma_{\mathrm{d}} \\
\left(\times 10^{4}\right)\end{array}$ \\
\hline 1 & 45 & 0 & 0 & 0.4 & 0.6 & 2.16 & 12000 & 19 \\
\hline 2 & 40 & 10 & 0 & 0.4 & 0.6 & 2.25 & 8200 & 130 \\
\hline 3 & 20 & 20 & 0 & 0.8 & 0.7 & 2.36 & 420 & 2.8 \\
\hline 4 & 10 & 40 & 0 & 0.4 & 0.6 & 2.58 & 1.7 & $>4.6$ \\
\hline 5 & 5 & 10 & 75 & 0.8 & 2.5 & 2.40 & 77 & 18 \\
\hline 6 & 3 & 12 & 75 & 0.8 & 3.0 & 2.43 & 61 & 4.8 \\
\hline 7 & 0.75 & 3 & 75 & 0.8 & 3.0 & 2.14 & 960 & 35 \\
\hline 8 & 0.75 & 3 & 75 & 1.6 & 3.0 & 2.21 & 740 & 25 \\
\hline 9 & 1.5 & 20 & 86 & 0.8 & 3.0 & 2.59 & 1.6 & $>3.8$ \\
\hline 10 & 0.75 & 10 & 89 & 0.8 & 3.0 & 2.38 & 4.3 & $>2.1$ \\
\hline 11 & 0.75 & 10 & 89 & 0.8 & 3.0 & 2.41 & 4.5 & $>1.5$ \\
\hline
\end{tabular}


$\mathrm{SiH}_{4}$ plus $\mathrm{CH}_{4}$ flow) ranged from 0 to 20 , and the $\mathrm{CH}_{4}$ to $\mathrm{SiH}_{4}$ ratio from 0 to 14 . The substrate temperature was varied from 160 to $300^{\circ} \mathrm{C}$. The rf power was varied from 0.4 to $1.6 \mathrm{~W}$. Table 1 shows the deposition conditions used. Samples were deposited simultaneously on Corning 7059 glass and crystalline silicon substrates.

We determined sample thickness and growth rate by step profilometry. We define the 'semi-transparency' gap, $E_{\mathrm{s}}$, as the photon energy where the absorption coefficient is $5 \times 10^{4} \mathrm{~cm}^{-1}$. (At this energy, approximately half the photons are transmitted through a $1000 \AA$ film.) We calculated the semi-transparency gap, $E_{\mathrm{st}}$, from optical transmission spectra. We measured the dark conductivity $\left(\sigma_{d}\right)$ and the 1-sun photoconductivity $\left(\sigma_{\mathrm{ph}}\right)$ at room temperature with parallel, coplanar $\mathrm{Cr}$ contacts.

In the $\mathrm{p}-\mathrm{i}-\mathrm{n}$ cells, boron-doped $\mathrm{a}-\mathrm{SiC}: \mathrm{H}$ was prepared from 0.6 Torr total pressure of $\mathrm{SiH}_{4}, \mathrm{CH}_{4}$, and $3 \%$ trimethelboron $(\mathrm{TMB})$ in $\mathrm{He}$, at flow rates of 25,50 and $7 \mathrm{sccm}$, respectively. The substrate temperature was $250^{\circ} \mathrm{C}$ and the $\mathrm{rf}$ power was $0.4 \mathrm{~W}$. This material is the a-SiC:H p-layer typically used as a window-layer in our standard a-Si:H solar cells and has $E_{\mathrm{st}} \approx 2.4 \mathrm{eV}$ and a room-temperature conductivity of $1.2 \times 10^{-6} \mathrm{~S} / \mathrm{cm}$. The n-layer was a microcrystalline silicon layer also adopted from our standard a-Si:H cells. Its deposition parameters were $\mathrm{SiH}_{4}$ and $3 \% \mathrm{PH}_{3}$ in $\mathrm{He}$ at 0.9 and $0.8 \mathrm{sccm}$, respectively, with $90 \mathrm{sccm} \mathrm{H}_{2}$ dilution, at 3.0 Torr, $200^{\circ} \mathrm{C}$, and $1.5 \mathrm{~W}$. This material has a room-temperature conductivity of $63 \mathrm{~S} / \mathrm{cm}$. The i-layer material (\#5 in Table 1) was selected from the set of a-SiC:H depositions as described below.

We fabricated thin film PV cells on textured $\mathrm{SnO}_{2}$ tin oxide coated Corning 7059 glass. The cell structure was glass $/ \mathrm{SnO}_{2} / 100 \AA$ p-layer $/ 1500 \AA$ ilayer $/ 250 \AA \mu \mathrm{c}-\mathrm{n}$-layer/Pd. We measured the current-voltage $(J-V)$ characteristics of the cells under 1-sun illumination through the glass substrate. The transparency of the cell. without a Pd back contact, was evaluated by transmission spectroscopy.

We tested the electrical compatibility of the PV and EC devices by placing them side-by-side under 1-sun illumination with external electrical connections. This configuration simulates the monolithic device shown in Fig. I, but with external electrical connections. The changes in the white light transmis-

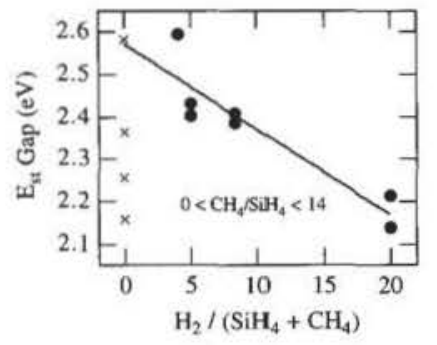

Fig. 2. Semi-transparency gap, $E_{\mathrm{st}}$, as a function of $\mathrm{H}_{2}$ dilution ratio. Crosses indicate samples with no $\mathrm{H}_{2}$ dilution and various $\mathrm{CH}_{4}: \mathrm{SiH}_{4}$ ratios. Filled points indicate those with non-zero $\mathrm{H}_{2}$ dilution.

sion of the EC device were monitored with a shortcircuited Si photodiode behind the EC device. We measured the voltage and current supplied by the PV cell and simultaneously the transmittance of the EC device as a function of time after the two devices were connected.

\section{Results}

Table 1 shows the results of the optical and electrical measurements on the set of intrinsic films. Fig. 2 shows the semi-transparency gap as a function of the hydrogen dilution ratio. Fig. 3 shows the transmission spectrum and 1 -sun $J-V$ curve for the cell fabricated with an i-layer of the target material (\# 5). The cell has a $J_{\mathrm{sc}}$ of $3.9 \mathrm{~mA} / \mathrm{cm}^{2}$, a fill-factor of 0.58 , and an $V_{\mathrm{oc}}$ of $0.92 \mathrm{~V}$. Its transparency is

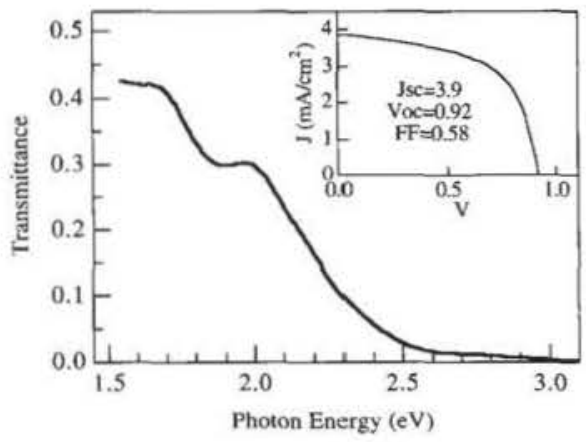

Fig. 3. Optical transmission spectrum and 1 -sun $J-V$ characteristic of the transparent PV cell using the target a-SiC:H i-fayer material. 


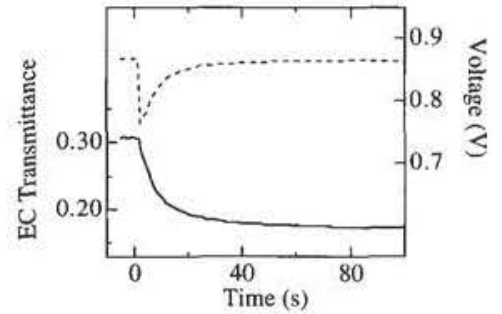

Fig. 4. White light transmission through an EC device and the switching voltage supplied by the a-SiC:H PV cell under 1-sun illumination as a function of time as the EC device is colored. The $\mathrm{EC}$ transmission is cut by about $50 \%$ by the use of a thin Au top contact instead of transparent $\mathrm{SnO}_{2}$.

between $30 \%$ and $40 \%$ at long wavelengths (below $2.0 \mathrm{eV}$ ). With white-light back illumination, it appears pale yellow-orange.

Fig. 4 shows the voltage and transmission transients for the side-by-side bench test of PV and EC integration. The EC device is described elsewhere [14]. When the electrical connection is completed, the EC device transmission drops within one minute to about half its bleached-state transmittance, while the voltage required to achieve this coloration remains below $0.87 \mathrm{~V}$. The coloration current is related to the PV voltage by its $J-V$ characteristic as shown in Fig. 3.

\section{Discussion}

For films without hydrogen dilution, the semitransparency gap increases from 2.16 to $2.58 \mathrm{eV}$ and the photo-to-dark conductivity ratio drops from 1.3 $\times 10^{6}$ to $2.8 \times 10^{4}$ as the methane fraction increases. For samples grown with hydrogen dilution, $E_{\mathrm{st}}$ is well correlated to the hydrogen dilution ratio, with a weak dependence on the methane-to-silane ratio. In this regime, samples with widely varying methane-to-silane gas-flow ratios, but the same hydrogen dilution, produce comparable optical gaps.

Several samples had semi-transparency gaps near our target of $2.4 \mathrm{eV}$ : Samples 3, 5, 6, 10 and 11. As these samples were deposited with widely varying deposition conditions, the photoconductivities of these samples ranged from $4.3 \times 10^{-9}$ to $4.2 \times 10^{-7}$ $\mathrm{S} / \mathrm{cm}$ and the photo-to-dark conductivity ratios varied from at least $1.5 \times 10^{4}$ to $1.8 \times 10^{5}$. Because of its semi-transparency gap of $2.40 \mathrm{eV}$ and good photo-to-dark conductivity ratio of $1.8 \times 10^{5}$, we chose sample 5 as the candidate i-layer material for the transparent PV cell.

The cell transparency is good below $2.0 \mathrm{eV}$, although still less than our target of $70 \%$. There are undoubtedly many contributions to the excessive absorption of the PV cell. An important source of this absorption is our use of textured $\mathrm{SnO}_{2}$ substrates, which causes significant undesirable light trapping. Above $2.0 \mathrm{eV}$ the absorption is also much larger than desired. The i-layer material is semi-transparent at $2.4 \mathrm{eV}$, but is too thick. Another possible source of the significant cell absorption between 2.0 and 2.4 $\mathrm{eV}$ is the un-optimized $\mathrm{p}$ - and n-layers.

\section{Conclusions}

We have fabricated semi-transparent PV cells for use in monolithic PV-EC devices. The long wavelength transparency of our best cell remains below our design target. Transparency will be improved by incorporating thinner cell layers and more transparent, lower haze $\mathrm{SnO}_{2}$. In addition, the large blue absorption in the cell, not found in the i-layer material, suggests that improvements in the doped layer transparencies are needed.

The $V_{\mathrm{oc}}$ of this cell is close to our $1.0 \mathrm{~V}$ target. The $J_{\mathrm{sc}}$, however, is at least one order of magnitude larger than our target. Given the excessive absorption in the cell, we will try to trade off the excess current for increased transparency in future cells.

A side-by-side bench test of the electrical compatibility of our PV and EC devices showed that we can achieve good coloration with good switching speed with voltages well below $1 \mathrm{~V}$. Thus we fully expect that a monolithic PV-EC device will function similarly.

\section{Acknowledgements}

The authors thank Richard Crandall, Ed Tracy and Satyen Deb at NREL for helpful discussions. This work was supported by OER/BES Advanced Energy Projects of DOE under contract No. DEAC36-83CH10093. 


\section{References}

[1] W.A. Bartovics, Masters Thesis, MIT (1984).

[2] S. Selkowitz and C.M. Lampert, in: Large-area Chromogenics: Materials and Devices for Transmittance Control, ed. C.M. Lampert (Optical Engineering Press-SPIE, Bellingham, WA, 1990) p. 504.

[3] S. Reilly, D. Arasteh and S. Selkowitz, Solar Energy Mater. 22 (1991) 1.

[4] D.K. Benson and H.M. Branz, Solar Energy Mater. 39 (1995) 203.

[5] H.M. Branz, R.S. Crandall and C.E. Tracy, Patent No. 5377 037, Midwest Res. Inst. (1994).

[6] S.K. Deb, Appl. Opt. Suppl. 3 (1969) 193.
[7] S.K. Deb, Philos. Mag. 27 (1973) 801.

[8] G. Hollinger, T.M. Duc and A. Deneuville, Phys. Rev. Lett. 37 (1976) 1564.

[9] R.S. Crandall and B.W. Faughnan, Phys. Rev, Lett. 39 (1977) 232.

[10] O.F. Schirmer, J. Electrochem. Soc. 124 (1977) 749.

[11] B.W. Faughnan, R.S. Crandall and P. Heyman, RCA Review 36 (1975) 177

[12] R.D. Rauh and S.F. Cogan, J. Electrochem. Soc. 140 (1993) 378.

[13] J.N. Bullock and H.M. Branz, SPIE: Optical Materials Technology for Energy Efficiency and Solar Energy Conversion (1995).

[14] C. Bechinger, private communication (1995). 